\title{
CONSTANT-CURRENT CHARGING SUPPLIES FOR THE ADVANCED PHOTON SOURCE (APS) LINEAR ACCELERATOR MODULATORS
}

\author{
R. Fuja, A. E. Grelick, D. Meyer, G. Pile, and M. White \\ Advanced Photon Source, Argonne National Laboratory, \\ 9700 South Cass Avenue, Argonne, Illinois 60439-4800 USA
}

\section{Abstract}

The APS $[1,2]$ linac beam energy must be stable to within $\pm 1 \%$ to match the energy acceptance of the positron accumulator ring. The klystron pulse modulators $[3,4]$ must therefore provide a pulse-to-pulse repeatability of $0.1 \%$ in order for the beam to have the required energy stability. The modulators have had difficulty achieving the necessary repeatability since the pulse forming network (PFN) charging scheme does not include a deQing circuit. Several of the major charging circuit components are also less reliable than desired. In order to increase operating reliability and to improve pulse-to-pulse stability, it is planned to replace the high voltage power supplies in all modulators with constantcurrent power supplies. A new modulator charging supply that contains two EMI [5] series 303 constant-current power supplies was constructed. Each of these EMI supplies delivers $1.5 \mathrm{~A}$ at up to $40 \mathrm{kV}$. One supply is sufficient for linac operation at up to $45 \mathrm{~Hz}$, and two supplies in parallel enable linac operation at the nominal rf repetition rate of $60 \mathrm{~Hz}$. This paper discusses test results from the new modulator, and also describes the existing modulators and their performance limitations.

\section{INTRODUCTION}

In the five existing APS linac modulators, a 12-pulse unregulated power supply and a 22-Henry inductor are used to resonantly charge a $0.704-\mu \mathrm{F}$ PFN capacitance to the desired voltage through a tetrode switch tube. When the switch opens, energy in the charging inductor increases the PFN voltage to a higher value. This new PFN voltage level can vary from pulse to pulse depending on the voltage level of the charging supply. The charging supply's output voltage is affected by the rather frequent $\mathrm{AC}$ line voltage fluctuations. The $60-\mathrm{Hz}, 20 \mathrm{kV}$ charging supply. the tetrode switch tube. the 22-Henry charging inductor, and other ancillary equipment require control and protection circuitry and also a fair amount of space.

The heat generated by the 100-A tetrode filament current must also be dealt with. Use of a series tetrode as the charge-controlling element is not ideal, because screen grid current can become excessive as the plate voltage drops to a value near the screen grid voltage.

The PFN is normally charged to $33 \mathrm{kV}$, and for $\pm 0.1 \%$ regulation. $\mathrm{a} \pm 33 \mathrm{-V}$ variation can be tolerated. Use of a 22-Henry charging inductor means that the current in the inductor is required to remain to within $\pm 5 \mathrm{~mA}$ at the time the tetrode opens. This is impossible in this nondeQed configuration because of the large stored energy in the inductor.

AC line variations of $3 \%$ can easily be seen during normal running, and power line variations of $5 \%$ can happen at certain times of the day.

In order to overcome the limitations of the present configuration, a sixth modulator and klystron system, eventually intended as an on-line spare, was fitted with two EMI series 303 constant-current charging supplies. These supplies are rated at $40 \mathrm{kV}$ and $1.5 \mathrm{~A}$, and are capable of an average power output of $30 \mathrm{~kW}$. In the next section, we compare regulation of the new modulator with constant-current supplies to regulation of our standard modulators with resonant-charging systems.

\section{TEST RESULTS}

Power supply regulation data were obtained for both types of charging systems while the $1000-\mathrm{A}, 2-\mathrm{Hz}$ pulsed, booster synchrotron power supplies were off and also while they were on. The modulator PFN set point voltage, the actual measured modulator PFN voltage, and the incoming $\mathrm{AC}$ line voltage were logged and analyzed using software from the SDDS toolkit [6]. Power supply regulation data for the two types of charging systems were captured using the built-in envelope detector on an HP 54542 A oscilloscope.

With the booster synchrotron pulsed supplies ramping at full power, there are PFN voltage variations of $\pm 0.55 \%$ when the resonantly-charged PFNs are charged to $33.9 \mathrm{kV}$, as can be seen in Figure 1. With the booster supplies off, the PFN voltage regulation provided by the resonant-charging system was $\pm 0.3 \%$ of $32.5 \mathrm{kV}$.

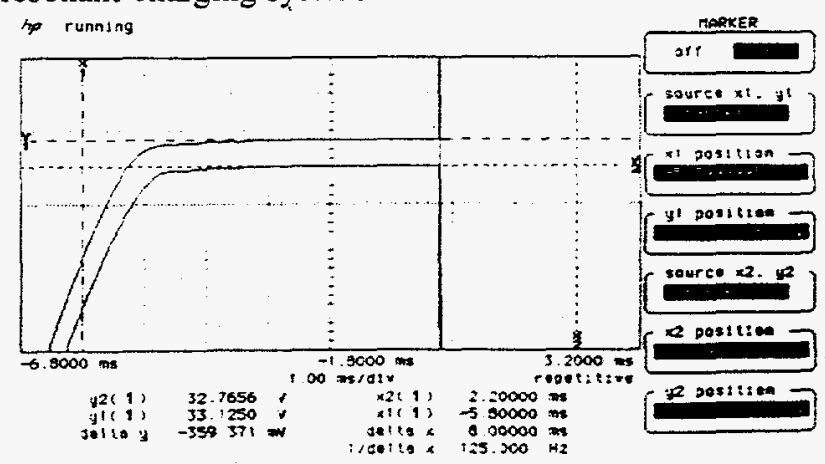

Figure 1: The resonant-charging system regulates to $\pm 0.55 \%$ with the $2-\mathrm{Hz}$ synchrotron pulsed supplies on.

The submitted munuscript has been created by the Liniversiry of Chicago as Operator of Argonne National Laboratory ("Argonne") under Contract No. W-31-109-ENG-38 with the US. article to reproduce, prepare derivative works. distribute copies to the public, and perform publicly and display publicly, by or on behalf of the Government. 


\section{DISCLAIMER}

Portions of this document may be illegible in electronic image products. Images are produced from the best available original document. 


\section{DISCLAIMER}

This report was prepared as an account of work sponsored by an agency of the United States Government. Neither the United States Government nor any agency thereof, nor any of their employees, makes any warranty, express or implied, or assumes any legal liability or responsibility for the accuracy, completeness, or usefulness of any information, apparatus, product, or process disclosed, or represents that its use would not infringe privately owned rights. Reference herein to any specific commercial product, process, or service by trade name, trademark, manufacturer, or otherwise does not necessarily constitute or imply its endorsement, recommendation, or favoring by the United States Government or any agency thereof. The views and opinions of authors expressed herein do not necessarily state or reflect those of the United States Government or any agency thereof. 
The constant-current charging system heid the PFN voltage to $\pm 0.125 \%$ with the booster pulsed supplies ramping at full power and with the PFN charged to $31.6 \mathrm{kV}$, as can be seen in Figure 2. The constant-current supplies regulated the PFN voltage to $\pm 0.125 \%$ of 31.3 $\mathrm{kV}$ with the booster pulsed magnets off. The constantcurrent charging supplies were operated in pulsed mode, with charging initiated for $12 \mathrm{~ms}$ at a $30-\mathrm{Hz}$ rate.

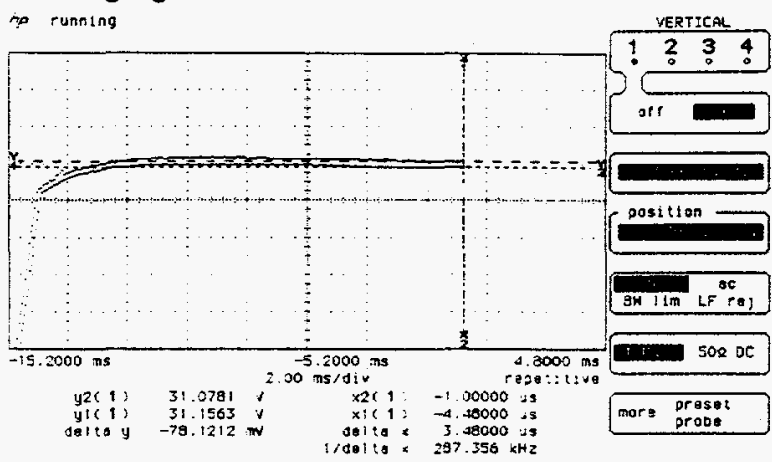

Figure 2: The constant-current charging system regulates to $\pm 0.125 \%$ with $2-\mathrm{Hz}$ synchrotron pulsed supplies on.

Figure 3 shows variations in the PFN voltage and in the line voltage over a six-hour period on a typical day. The PFN set-point was constant during this period. Figure 3(a) shows the actual PFN voltage during that time, and Figure 3(b) shows variations in line voltage over the same time period. The measured PFN voltage follows the AC line voltage quite closely.
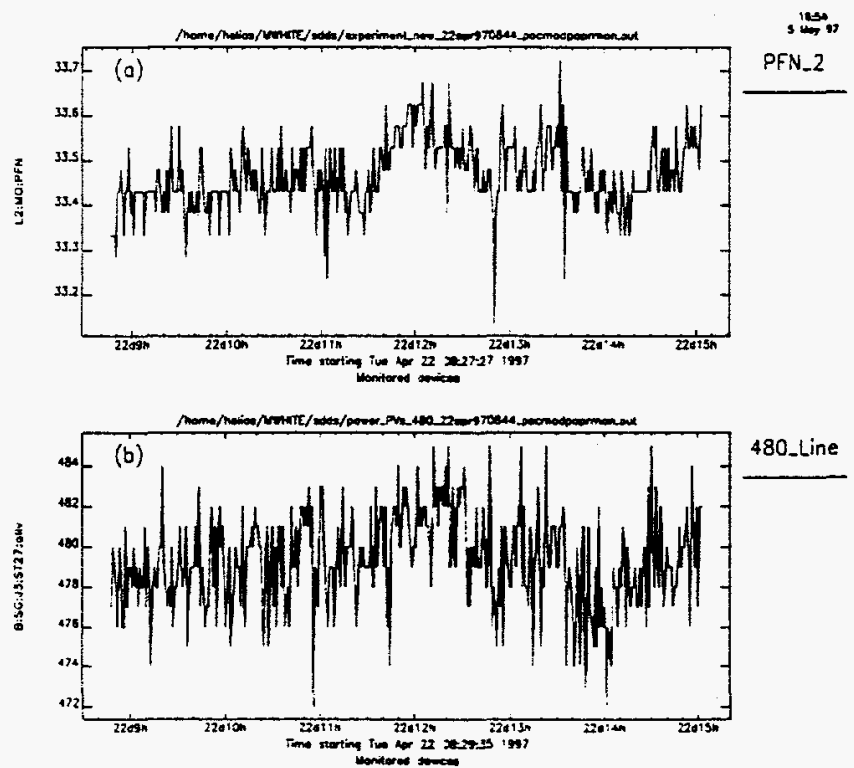

Figure 3: (a) PFN voltage and (b) AC line voltage variations over a six-hour period.

\section{DISCLSSION}

The resonant-charging system, as presently configured. is inadequate to provide a regulation of better than $\pm 0.55 \%$ under changing line voltage conditions, as can be seen very clearly in Figure 4. Figure + is a single-shot plot of a resonantly charged PFN taken while the boosier synchrotron supplies were pulsing at full power and at a 2- $\mathrm{Hz}$ rate.

The effect of the 2-Hz pulsed synchrotron supplies on the regulation of the PFN charged by constant-current supplies is not evident, as shown in Figure 5.

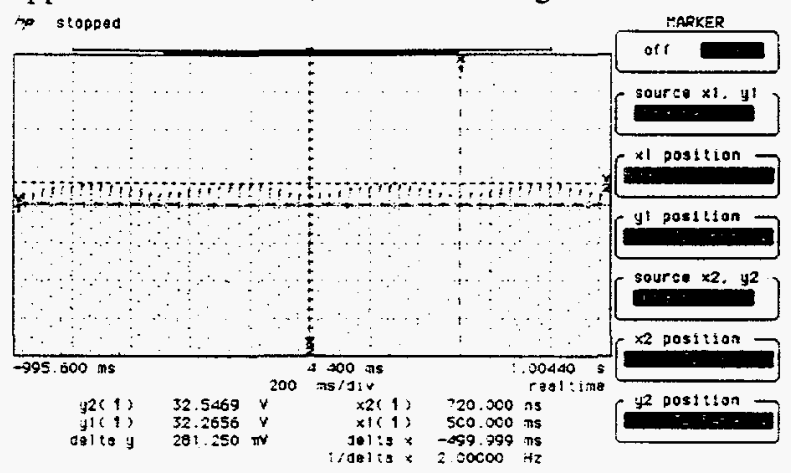

Figure 4: The 2-Hz pulsing of the synchrotron supplies appears as an inter-pulse ripple on the voltage of the resonantly-charged PFN.

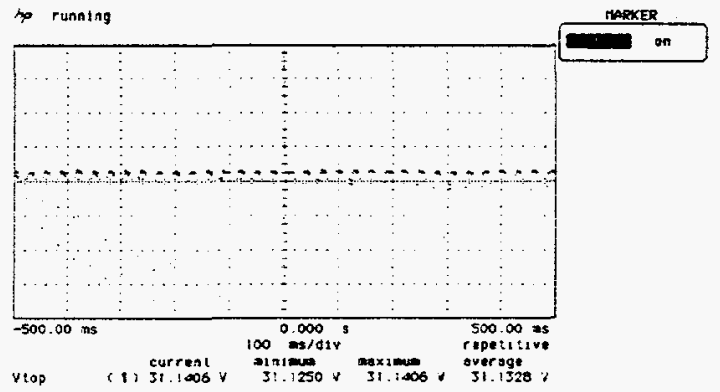

Figure 5: Regulation of constant-current supplies with pulsed supplies running at full power and at a $2-\mathrm{Hz}$ rate.

\section{CONCLUSION}

Under constant AC line voltage conditions, the regulation produced by the two different charging systems is quite similar. The difference becomes evident as the AC line varies, and poor regulation sometimes even leads to operational difficulties. Although data are not presented here, the PFN voltage for some of the resonantly charged systems has been observed to vary as much as $1 \mathrm{kV}$ out of $33 \mathrm{kV}$. The constant-current supplies are able to charge the PFN to within $\pm 39 \mathrm{~V}$, independent of the actual PFN voltage level.

Both charging systems have experienced reliability difficulties. One of the tetrode circuits had a chronic problem with oscillations that proved extremely difficult to control and has led to a number of tube failures. One constant-current supply experienced several infantmortality failures, including one that caused oscillations. In the long term however, it is expected that use of the semiconductor-based power supplies will result in a modulator availability that is superior to that of the resonant-charging circuit with a tube.

The new modulator supplies are very compact, freeing up a lot of real estate as shown in Figure 6. We are able to 
eliminate a moturized 3-phase variable transformer, a high voltage step-up transformer. a high voltage rectifier assembly, a switching elemen. and a charging inductor, along with related control and satety circuitry. The standard dosble-width rack th: contains most, but not all, of the resonani-charging : $: 5 \mathrm{~m}$ components is shown in Figure 7. An additional outsard sabinet. not shown, is also required

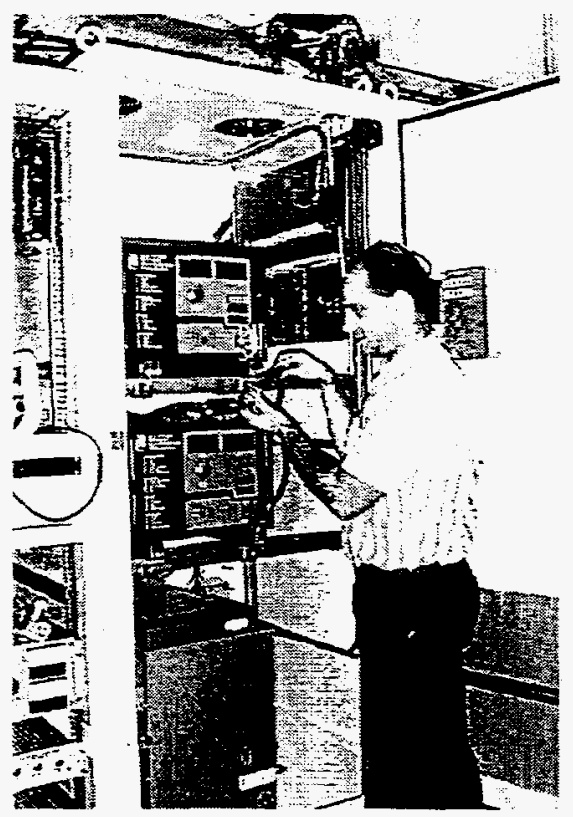

Figure 6: One single-width cabinet contains two constantcurrent power supplies.

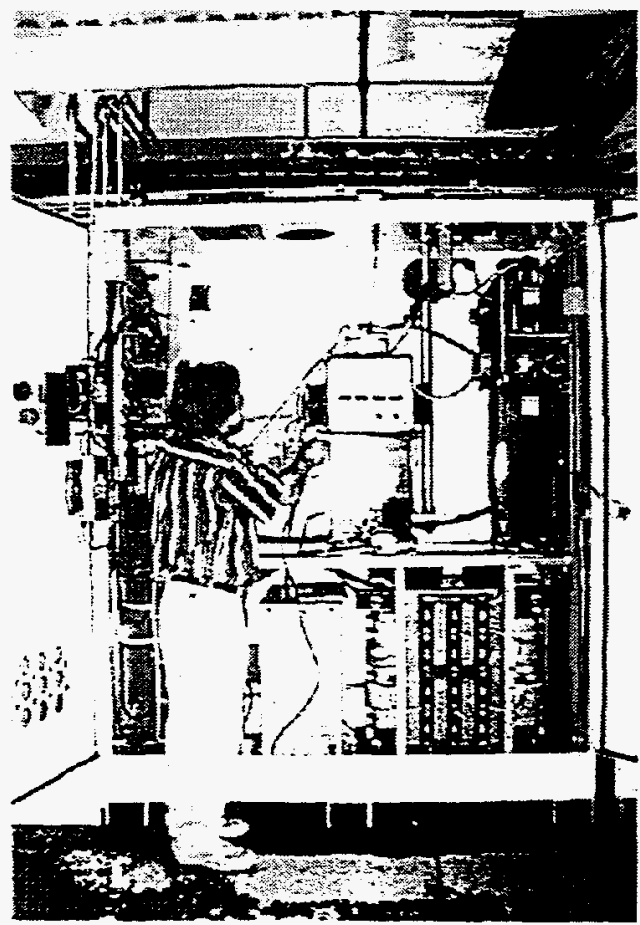

Figure $7:$ A double-width high voltage power supply eabiner wntwns must w the :esonant-charging system.
A new control system is being developed that will incorporate the built-in diagnostic functions of the constant-current supplies and will eliminate unneeded functions in the existing control system. Considerable attention will be devoted to signal and power filtering, cable and connector shielding, electronic chassis screening, and chassis and rack grounding. The system will be modular, utilizing commercially available PLC technology, but will be re-engineered into an environment that will make it much less susceptible to interference or failure.

Large power system transients have been experienced during klystron conditioning. High voltage transient breakdowns or "arcs" have previously caused component failures in the existing power and control systems. These types of problems cause radio frequency interference (RFI). The effects are mostly seen as pickup on signal cables, and they result in spurious operation of interlocks as well as erratic behavior of electronic circuits. RFVelectromagnetic-compatibility testing, utilizing bulkcurrent injection and conducted-emission techniques, will be used on the new control system. These tests will help to make the new control system reliable without compromising the high bandwidth required of its control and monitoring circuits.

\section{ACKNOWLEDGMENTS}

Work is supported by the U.S. Department of Energy, Office of Basic Energy Sciences, under Contract No. W-31-109-ENG-38. Many thanks to G. Trento and $T$. Jonasson for assembling the sixth modulator and for adapting the new charging system to the existing control system.

\section{REFERENCES}

[1] "7-GeV Advanced Photon Source Conceptual Design Report," ANL-87-15, April 1987.

[2] M. White et al., "Construction, Commissioning, and Operation of the Advanced Photon Source (APS) Linear Accelerator." Proc. of the XVIII International Linac Conference, Geneva Switzerland, 26-30 August 1996, pp. 315-319.

[3] T. Russell and A. Cours, "Klystron Modulator Operation and Upgrades for the APS Linac," Proceedings of the 1995 Particle Accelerator Conference, 1-5 May 1995. Dallas, Texas, pp. 15591561 (1996).

[4] "APS Linac Klystron and Accelerating Structure Gain Measurements and Klystron PFN Voltage Regulation Requirements." N. S. Sereno. LS : Vote 257, April 1997.

[5] Electronic Measurements Inc. 405 Essex Rd. Neptune. N]. 07753.

[6] M. Borland and L. Emery, "The Self-Describing Data Sets File Protocol and Toolkit," Proceedings of the 1995 ICALEPCS Conference. pp. 653-662 (1997). 